\title{
The use of Human Resource Management Systems in the Saudi market
}

\author{
Bandar Khalaf Alharthey • Amran Rasli
}

Received: 7 November 2011 / Accepted: 2 January 2012 / Published online: 18 January 2012

(C) Springer Science+Business Media B.V. 2012

\begin{abstract}
The goal of the study was to investigate the current situation with Human Resources (HR) systems in the Saudi market on the basis of survey conducted among 100 organizations. Their HR and IT experts were to fill out a questionnaire that allowed receiving their expert opinion and make conclusions considering the HR systems usage in this country. In the course of the study, eight hypotheses were investigated and proved: the number of companies' users of Human Resource Management (HRM) systems does not exceed a half of the staff; most companies use additional resources for HR management apart from HR automated systems; many companies use systems developed by their specialists for HRM; companies are satisfied with the level of HRM systems' performance; companies are ready to implement new, more effective systems in their practice; Saudi market is not ready for SaaS model; companies are not ready to implement SaaS model; companies have high development potential despite impediments. The results have shown that the Saudi market is ready for implementation of the new technologies, while the level of satisfaction by the current solutions is comparatively low and requires urgent measures. New developments, preferably on the basis of SaaS model, are required to improve the situation and make a step towards successful future.
\end{abstract}

Keywords HRM systems $\cdot$ SaaS model $\cdot H R$ in Saudi · On-demand software $\cdot$ Human capital management · Talent management · Human Resource Management system

\section{Introduction}

Human Resources (HR) systems are the electronic tools used to access HR-related information and perform HR-related functions (Human Resources Systems 2011;

B. K. Alharthey $(\square) \cdot$ A. Rasli $(\square)$

Department of Management, Faculty of Management and Human Resource Development, University Technology of Malaysia, 81310 UTM, Johor Bahru, Johor, Malaysia

e-mail: b4n-99@hotmail.com

e-mail: ameer_1430@hotmail.com 
HRMS 2012). They are constantly being improved and developed around the world, offering more and more opportunities to HR managers. For many years, these systems already serve people for the purpose of better work's organization and enhancing HR department's work (Beaman et al. 2000). Within its history, the focus of HR systems moved from automation of personnel account to actual human resource management (Heathfield 2012; Hendry 1999). It means that today, it is not enough just to keep record of the staff, it is necessary to manage people, turning human resource into assets. HRM systems became especially topical after 2001, when there increased a number of people working from home (Evolution of HR Systems 2010).

Today, there is a tendency among fast-growing and developing companies in the USA to allocate considerable amount of funds for HRM purposes, including IT systems (Gatewood et al. 2008). Mostly, they are deigned to automate routine daily work and to keep record of all the necessary data. Now these systems mostly involve such modules:

1. Payroll. It automates the process of calculating payment for employees on the basis of attendance, deducting fines, and taxes and with any other aspects taken into account

2. Work time. It records the time of employees' work. Furthermore, it analyzes costs and work efficiency

3. Benefits administration. It is a system designed to administer employee's participation in benefits programs

4. HR management. This module records and analyzes all the data on employees and covers many different HR aspects

5. Recruiting. Online recruiting has already become one of the main sources of employees for organizations

6. Training. This module tracks all the data on employees' development and training; and other modules (Hunter et al. 2006).

Although the history of implementing HRM systems already counts many years, their results are still not as good as HR experts want them to be. For instance, according to PMP research conducted in 2007 by the Evaluation Center, one-third of the companies using these systems are dissatisfied with the systems' work (HR Systems Disappointing 2007). The survey included responses from 100 organizations from different sectors. Another important result was the main characteristic, according to which companies gave their preference to the particular systems - it is cost ( $80 \%$ of respondents), then goes flexibility, integration, and functionality. So, it is evident that in the world the situation with HRM systems still has to be considerably improved.

One of the main disadvantages of most software programs is that business can outgrow them with time. And when it happens, finding other solution is often hard for companies. Employees are usually also dissatisfied with the necessity of constant training with new programs. If we add the time necessary to train workers to the money that is needed to upgrade HR system of your choice, then it becomes evident that this method is not very suitable and winning for the business owners.

Still, there is a way out-high-quality HR systems envisage a possibility of growing along with the business. This possibility is realized through modifications 
applied to meet the growth and the changes in companies (Beaman et al. 2000). In some cases, management has a plan of action for the direction, in which the business will develop. There are also cases when tremendous growth takes off unexpectedly. Consumer trends also make their changes in the companies' state of affairs (Hendry 1999).

Since it is impossible to predict where business will be in a 1, 3, or 20 years, business owners should be ready for everything. Having a solid foundation for work in different spheres ensures that business is ready to face the challenges. Quality HR software is one of the complex actions necessary to be taken so as to have the flexibility of utilizing features that were not necessary for the business in the beginning. And it is especially convenient if such features are initially built into HR system and allow access to them at any time.

The way of communication and work with customers can also change over the course of time. When company identifies weak areas, in which it is not meeting clients' needs with maximum efficiency, a quality HR system can be customized and modified so as to work to business advantage. IT is evident that trying several formats is better than being locked into one. In this way, it will be easy to find the one that most suits the particular business and can make it really optimized (Beaman et al. 2000; Hendry 1999).

Business can also become more diversified than it has originally been. And it is absolutely necessary for HR software to be ready for such a change as well. For instance, initially business can have one product to offer its customers. But in the course of time business owner can see that his target market has another demand. If he succeeds to spot the tendency in the right time and offer the necessary product, he will have two products that are successfully bought by people. With proper HR system in business, he will be able to operate all the products without a need to get additional software.

One more way that a quality HR system can change along with business is that although some of them offer upgrades, for which it is necessary to pay considerable amount of money, there are solutions, in which all the upgrades are free, and managers have to pay only subscription fees (Hendry 1999). It is a convenient feature that allows to get updates to programs without buying anything else, and in such a way HR system will not ever become outdated.

It is necessary to take into account that there are constant changes taking place in the sphere of HR software production (Beaman et al. 2000). The new developments help to make sure that business operates as smoothly as it is possible. Employees in this way always have all the necessary tools for quick and successful work. At the same time, customers see the company as trustworthy and sophisticated, which encourages them to return to the company to make other purchases. Any HR system business uses has to be, first of all, current and reliable. In case it is outdated, company is sure to waste a lot of time and reduce its influence in the market.

When HR system is purchased, it needs to have everything organization needs, but at the same time it should have much to offer for the company's future. As managers explore different types of modern HR software, they will see how it is possible (Beaman et al. 2000). Often there is such a situation that business owners can find benefits offered along with certain versions of programs, which they have never heard of. But as soon as they get familiarized with them, they will have a vision of how to turn them into positive impact for business (Blokdijk 2008). 
Although after analyzing the advantages of different HR systems solutions, managers can understand their value, often there are situations when they think that such systems are not necessary for them. For instance, they can consider their type of business to be inappropriate for HR systems usage, or the peculiarities of their goods or services. Sometimes they think that the size of the business is too small for systems implementation, or on the contrary - it is so large that they think that the advertised product simply will not cope with it.

When the company's management thinks in such a way, the whole company suffers. Of course, it is possible for companies to function without such systems, but in fact their usage can be a huge time-saving opportunity (Blokdijk 2008). Besides, by using them, it is possible to avoid a large number of mistakes, as well as losses of information. Eventually, it is a money saving chance as well, as all the mistakes that can be missed, information that can be lost and other additional unnecessary expenses make economy on efficient HR software absolutely pointless (Hendry 1999).

So, it is evident that any business can receive real benefits from implementation of the HR software. Of course, finding the right HR software solution takes time, but it is important. If the right choice is made, the company will not have to adjust its course of affairs to the program - instead, the software will make business more organized and efficient (Beaman et al. 2000).

It is necessary to understand what business can get from HR system, as in fact it is much more than a means of keeping record of employees' working hours and vacation time. They can help determine the costs of work that business offers, so as to be sure that prices, for instance, are where they should be. They can also help create positive and professional image among customers and future employees.

With up-to-date HR system, it becomes very easy to pay employees for the completed work, as all their work time is automatically calculated and taxes and fines are deduced. Effective management of these nuances will make business well-organized and easy-tomanage. Moreover, employees will trust managers more, as they will see, on the basis of which they get bonuses, or for what they are fined (Blokdijk 2008). It is also possible to find a solution that will not cost too much, as there are such convenient solutions as SaaS that can considerably save your time and money.

Our research is focused around Saudi market. The market of HRM systems here is not developed enough, and many companies still continue such practices as keeping record of the HR aspects with the help of paper medium, or nonspecialized systems, such as MS Word, Excel, and Access. Competition in the sphere of specialized software is not significant. In this research the majority of companies use such programs as 1C, Boss-Kadrovik, SAP.

$1 \mathrm{C}$ and Boss-Kadrovik are systems developed by Russian companies that provide similar opportunities: record of employees' work time; record of salaries, record of deviation from the normal working schedule (vacations, days off, business trips, etc.); payment performance; calculation of taxes; personnel record; and other convenient functions. Still, the program 1C has negative feedback, which is directed at its comparatively high price and the necessity to employ a professional to work with it, as there are many features that have to be adjusted and changed at programming level (1C Company 2012). As for the second program-Boss-Kadrovik-there are complaints on its poor functionality and opportunities. In this respect, the last program - SAP - has more to offer, as it is possible with its help to do what the 
other two systems cannot, but at the same time it has its own drawbacks, such as difficulty of setting and maintenance, much time necessary for changes brought about by amendments in legislative system, high cost (SAP 2012).

So, the current supply is poor and does not satisfy the demands of modern Saudi companies. It is the main reason why it is necessary to take measures and find an effective solution. We offer considering SaaS model, which will be really effective in the Saudi market.

SaaS (Software as a service, also "On-demand software") is a model, in which software and all the corresponding materials and data are hosted on central basis, often in the Internet cloud, and are accessed by users via a thin client, usually through web browser (Software as a Service 2012). This model is today widely spread in different spheres, such as content management, HR, customer relationship management and others.

If we consider the sphere of HR in particular, we should state that on-demand HR software, depending on the provider and software peculiarities, offers users complete Human Capital Management (a.k.a. Talent Management) and/or complete Human Resource Management System applications. Often, the systems have direct links with internal databases and payroll providers so as to allow easy transference of data between programs.

There can be singled out the following advantages of SaaS (Facts about SaaS HR 2012):

- It is time and money saving (Williams 2009). On-demand HR software is, first of all, efficient. Installed software is usually very costly both at the stage of implementation and maintenance, while SaaS utilization requires paying monthly fees that are considerably lower than the first variant of HR software (Chang et al. 2010). It is also necessary to state that SaaS saves a great deal of money by the absence of necessity to install and maintain special hardware and pay personnel for providing the necessary back-up systems, installing and maintaining the programs, purchasing, maintaining, and housing servers (Blokdijk 2008). In this way, it is also much easier to plan the firm's budget in this aspect, as installed programs have much hidden costs, while on-demand software has none. Moreover, these systems are easy to install and adjust, as provider has everything that is necessary, all setup and working, including security protocols that guarantee complete confidentiality of all the data.

- It is convenient and does not have limits on access. Availability and convenience are among the main decisive factors when making a choice to buy this or that software (Velte et al. 2010). SaaS has a considerable edge over installed programs in this relation. For instance, they are maintained by the provider hosts, which means that the customer is not responsible for the software installation, maintenance and repairing if necessary. So, no special staff is required to do everything that is necessary (Mather et al. 2009).

- It is easy to change and adjust. Seas can easily grow along with the company (Hatch 2008). It is a common situation for a company to start with a certain number of functions, and then add new ones that are necessary for its growth. From the financial aspect, on-demand software allows organizations to pay for additional records or services as their own growth makes these payments more affordable. As companies add employees and expand, their proportionate increase in 
fees reflects their ability to pay. The majority of corporate finance executives admit that this scheme is much more equitable and manageable means of payment.

- It is easy to be configured to particular needs (Bocij et al. 2008). There are different structures of on-demand software. The ones that operate on a kind of architecture that is called single-tenant (another variant is multitenant system), can be easily configured in functionality so as to meet specific organizations' needs. The speed of such changes is much better than the one of the installed systems.

- It does not require expensive upgrades. When provider of installed software improves or upgrades its product, users have to pay the cost provider defines in the form of new license fees (Oshri and Kotlarsky 2010). With time, users that decide not to pay and upgrade might find that the expected services of their system are not available. In the world of SaaS, upgrades are performed at the provider's expense.

Thus, the system is a perfect variant for companies with much routine work that needs to be automated, although for companies that require subjective criteria and need special HR functions automation they may be not suitable (Moe 2010).

Our research is focused around the following objectives: identify the current use of HRM systems by Saudi companies; discover the level of users satisfaction with the systems they use; see how many users of HRM systems there are currently in the companies; see if there are additional resources used by the companies; discover whether companies are ready to implement new, more effective solutions into their practice; see if the Saudi market and customers are ready for SaaS model; identify the main obstacles on the way of new HRM systems implementation.

Hypotheses

On the basis of our study objectives, we developed the following hypotheses:

H1: The number of companies' users of HRM systems does not exceed a half of the staff.

H2: Most companies use additional resources for HR management apart from HR automated systems.

H3: Many companies use systems developed by their specialists for HRM.

H4: Companies are satisfied with the level of HRM systems' performance.

H5: Companies are ready to implement new, more effective systems in their practice.

H6: Saudi market is not ready for SaaS model.

H7: Companies are not ready to implement SaaS model.

H8: Companies have high development potential despite impediments.

\section{Methodology}

Participants and procedure

Companies with central offices in Al-Riyadh, Jeddah, and Al-Dammam region were involved in the research. The number of respondents exceeded 100 . The following 
sectors were covered: finance and audit, retail business, manufacturing, power engineering, housing and community amenities, construction, telecommunications, mass media, logistics, transport, automotive industry. Respondents of the companies were managers of HR and IT departments. Questionnaire consisted of a block with general questions and a block that allowed to receive expert opinion of the necessary questions. Among the investigated companies the most active were comparatively large organizations $(77 \%)$. The whole distribution by the number of staff is shown in Fig. 1.

\section{Results and analyses}

Hypothesis 1: The number of companies' users of HRM systems does not exceed a half of the staff

Although the number of staff in the companies under investigation was quite large, the number of HRM systems users in the majority of them (55\%) does not exceed 25 people. Detailed results are shown in Fig. 2. On the basis of this data, we can conclude that HRM systems are mostly used by HR managers and departments' directors. This situation should be changed so as all the companies' workers were involved in this work and could find all the necessary information on their work, efficiency and payment calculation. This will save a great amount of time for HR workers, and will optimize their work time. Moreover, employees will receive additional motivation factor for excellent performance and result-oriented work, as they will see what they are rewarded and fined for-the company's policy in this way will become clearer to them.

Hypothesis 2: Most companies use additional resources for HR management apart from HR automated systems

As the study showed, an overwhelming majority of respondents (70\%) in addition to the implemented systems use other resources. Fifty percent of them said that they use

Fig. 1 Number of staff in companies that took part in the

a over $300 \square 100-300 \square 50-100 \square$ less than 50 research

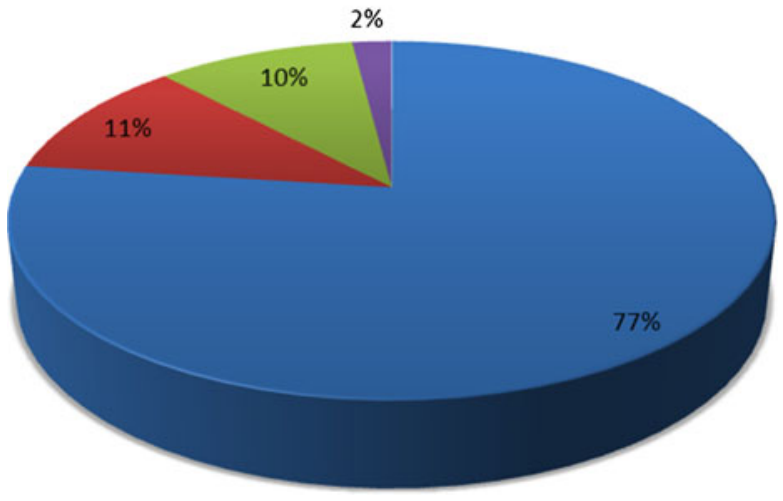


Fig. 2 Number of HRM systems users less than $25 \quad$ 25-50 $\square$ over 50

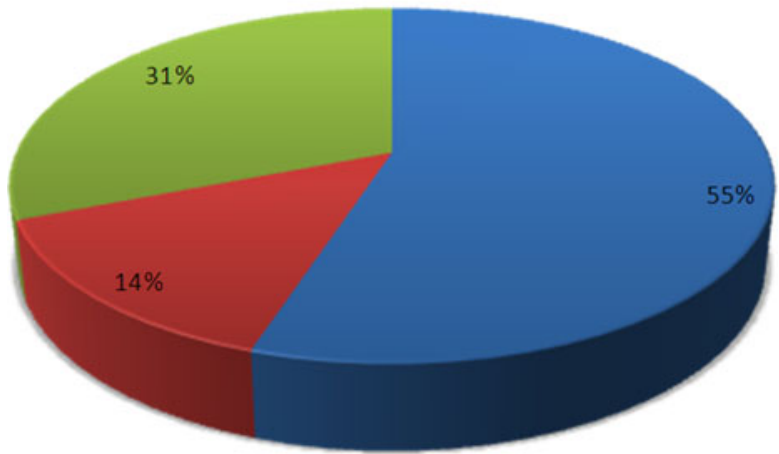

a combination of several resources and tools, among them not only specialized programs, but also paper medium. Detailed information on the resources is shown in Fig. 3.

On the basis of the discovered data, we have made the following conclusions:

1. As of today, there are still many people in the Saudi companies who do not use HRM systems optimally, and thus have to combine them with other tools and resources, the majority of which are already outdated and not used around the world.

2. Possible reasons for such reality can be inconvenience of the HRM systems; insufficient software localization - incompatibility of the programs' functionality with the peculiarities of the Saudi business needs and requirements; inadequate functionality; too high prices, etc.

3. In order to change and improve this situation, it is necessary to develop and implement campaign that will show advantages of the HRM systems, describe

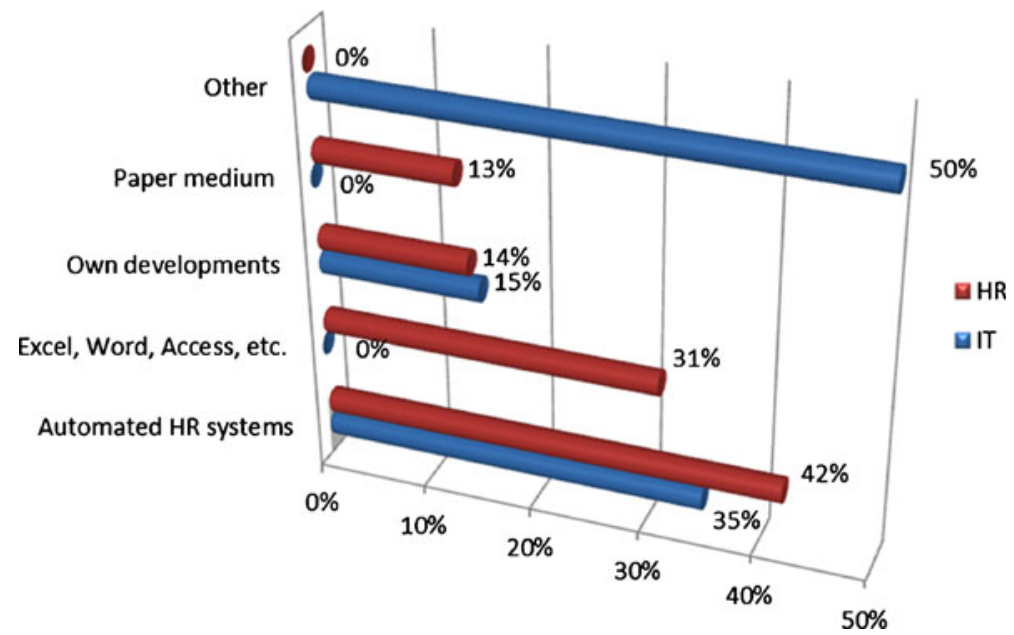

Fig. 3 Resources and tools used for recruiting, education and management of human resources 
their possibilities and the latest developments. Moreover, it is necessary to study the Saudi market more closely so as to develop systems that can fully satisfy all the needs and requirements of this sector.

Hypothesis 3: Many companies use systems developed by their specialists for HRM

The results of our study showed that a considerable number of HR systems users choose $1 \mathrm{C}$ system (34\%), and only a bit less of them use systems developed by their specialists $(30 \%)$. Detailed information is presented in Fig. 4.

Data of the research, first of all, affirms the conclusions we have drawn from Fig. 3-today HRM systems do not satisfy the demands of the Saudi business market, which is why they are used not to the fullest extent and are combined with different tools and resources. The data we got in this particular part of research also shows that one third of the companies use their own developments. It can be explained by the fact that system that is developed by the company's own IT expert fully satisfies this particular company's interests and can be adjusted to some new data or criteria at any moment that is necessary. Moreover, all the adjustments, updates, and changes will not bring additional expenses, and as it was already stated before, this aspect is one of the decisive ones when purchasing HRM systems. At the same time, for companies the necessity to develop their own systems is not always beneficial. In order to achieve long-term result and find a reliable solution, it is necessary to find and hire a professional that can cope with this task. Usually, work of such level of expert costs a lot, but it is evident that in this case companies are ready to pay some extra money to receive a product that will optimize their work and save money and time in perspective. It suits them more than using systems that have to be considerably adjusted to satisfy their needs, or simply cannot satisfy them at all.

Hypothesis 4: Companies are satisfied with the level of HRM systems' performance

According to the results obtained in the research, $40 \%$ of respondents are satisfied with the level of performance of HRM systems they are using. Still, there is a considerable number of people who assess their performance as satisfactory (24\%) and $16 \%$ as dissatisfactory. Detailed results interpretation is displayed in Fig. 5.

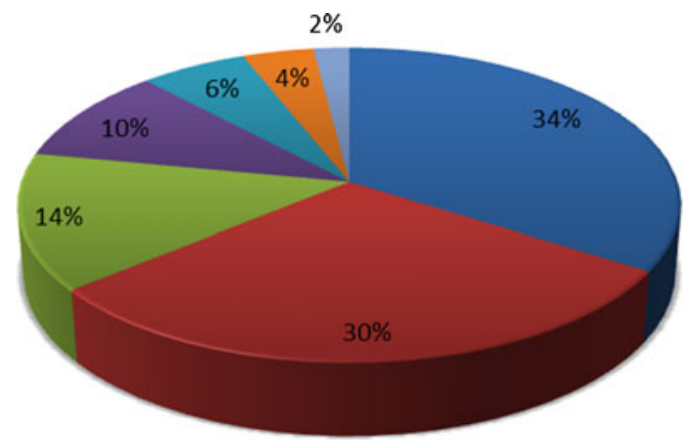

田 $1 \mathrm{C}$

घOwn development

$\square$ SAP

G Hard to answer

$\square$ Boss Kadrovik

Microsoft Dynamics

$\square$ Microsoft Access

Fig. 4 HRM systems used by Saudi companies 


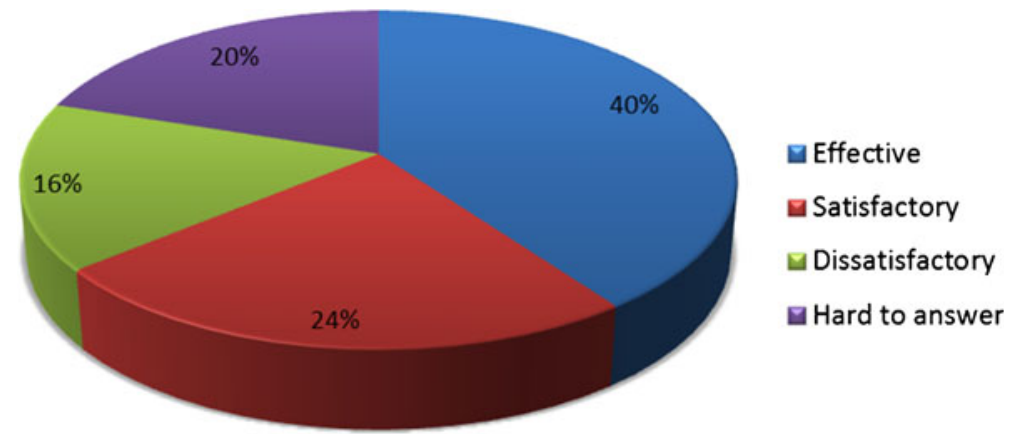

Fig. 5 Level of companies' satisfaction with HRM systems

The displayed results allow us to make the following conclusions:

1. Although the number of respondents who consider their systems to be effective almost reaches a half of the companies, it does not mean that the current systems work really effectively, as if we take into account the fact that there are about $30 \%$ of them using their own developments, we can see that the number of people who are satisfied with ready-made solutions is even less.

2. The fact that $60 \%$ of respondents did not assess their systems' work as effective supports our statement that there are new developments and implementations required that would change the situation and will make HR managers' work easier and optimized.

3. One fifth of the respondents did not have a definite answer to this question, which means that they are not informed enough about the systems work, or do not have enough experience working in it. It is also a disappointing result that requires urgent changes.

Hypothesis 5: Companies are ready to implement new, more effective systems in their practice

Respondents' answers show that practically all HR experts (92\%) of the considered companies realize that they need new HRM systems to be implemented, as they understand the positive influence they can have on their work. Detailed information on the received answers is shown in Fig. 6.

These results show that the Saudi business world is well aware of the effectiveness of HR systems, and although today there is no solution that completely satisfies their needs, they are ready to wait for an effective system that will be easy to maintain and use.

Hypothesis 6: Saudi market is not ready for SaaS model

According to the survey, $82 \%$ of respondents said that neither customers, nor suppliers were ready for SaaS model implementation. For detailed information on the respondents' answers, see Fig. 7. This result can be explained by the fact that SaaS model is not well-known for the Saudi market. In reality, it offers large 


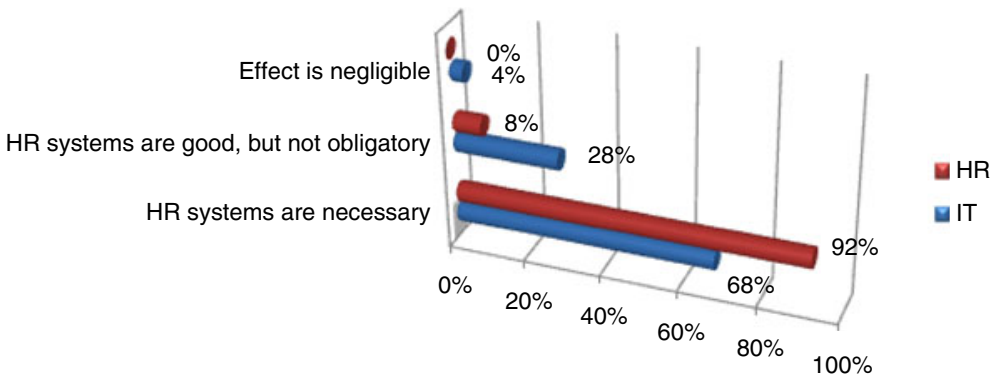

Fig. 6 Loyalty level to HR systems

possibilities to suppliers who will be able to develop and offer effective solution for SaaS model for the market. The market is ready for the new solutions, as our survey already showed, and SaaS model can become the best variant in this situation.

Hypothesis 7: Companies are not ready to implement SaaS model

Results of the survey show that only $8 \%$ of the companies are ready to implement SaaS model, and as many as $88 \%$ do not consider this possibility at all. Results are displayed in Fig. 8. Such distribution of answers can be explained by several factors:

1. Lack of people's knowledge about the system

2. Previous negative experience with HR systems

3. Investment into own developments and waiting for their positive results

But according to the fact that practically all the respondents are aware of the HRM systems necessity, an effective solution can change this tendency very quickly and without much effort.

Hypothesis 8: Companies have high development potential despite impediments

Among the main obstacles on the way of HR systems implementation there can be singled out seven major ones, such as: incompatibility with installed software, high cost, implementation difficulty, low interest from managers, change of business processes, absence of quality product, and staff resistance. Distribution of respondents' answers is shown in Fig. 9.
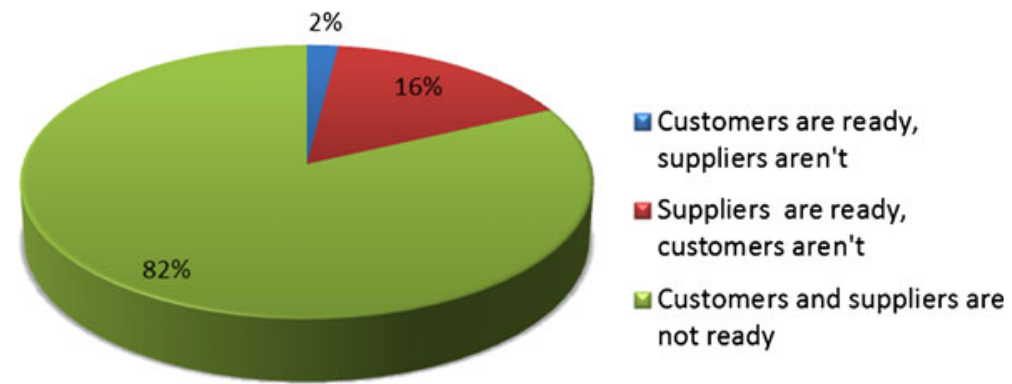

Fig. 7 Level of Saudi market readiness to SaaS model implementation 


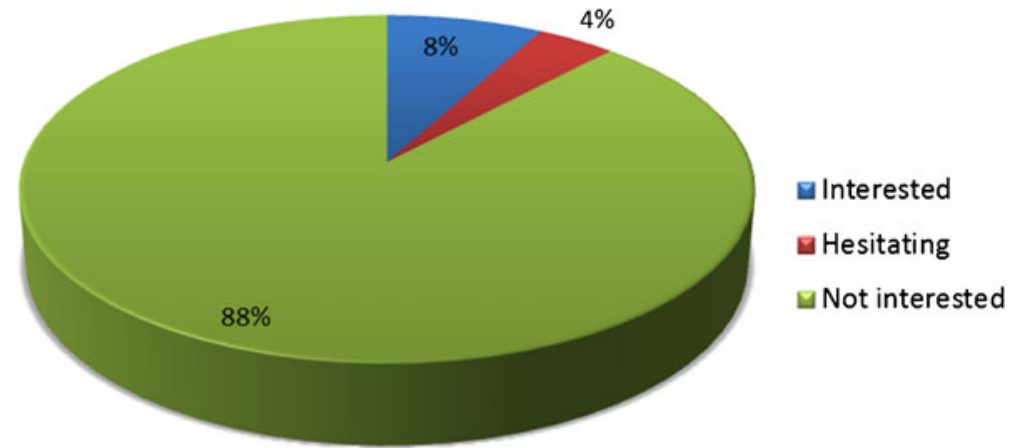

Fig. 8 Level of companies' readiness to SaaS model implementation

IT managers consider that the main obstacles on the way of HR systems implementation are low interest on the part of management $(23 \%)$ and staff resistance $(19 \%)$. What is interesting, HR managers consider the lack of interest from managers to be not such a big problem (only $14 \%$ consider it to be an obstacle) and staff resistance practically does not bother them at all (only $2 \%$ are worried about it). On the basis of this data, we can conclude that HR managers feel confident in their ability to persuade top management in the necessity of systems implementation and are absolutely ready for it. So, IT managers in these two aspects underestimated the HR sector's readiness for the changes.

The main obstacle in HR managers' view is incompatibility of new systems with the installed software (31\%). IT managers, in their turn, do not consider it to be a significant impediment (only $11 \%$ voiced their concern), which means that in this aspect HR department underestimates IT in their readiness for new technologies implementation. In the aspect of the cost obstacle, respondents from both departments see a major challenge at the same level-23\% HR and $22 \%$ IT.

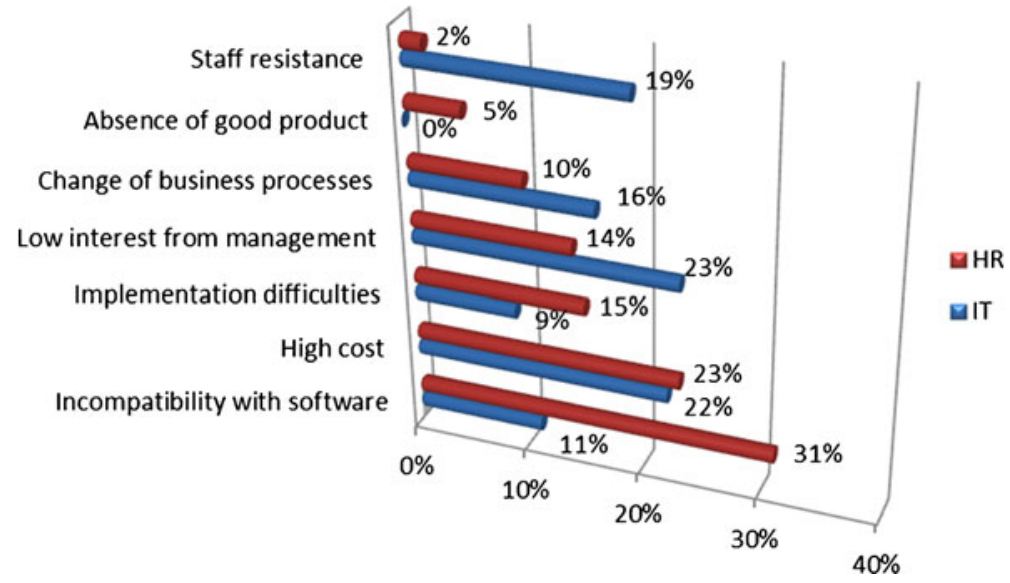

Fig. 9 Obstacles on the way of HR systems implementation 
Discussion on main findings regarding HRM systems hypotheses

On the basis of the findings described above it is possible to draw up the following conclusions:

1. Saudi market has favorable conditions for implementation of HR systems, which include awareness of the company's HR and IT managers in the necessity of such systems' implementation and absence of quality products that can satisfy the interests and demands of organizations.

2. The current software available on the market does not satisfy the majority of customers, as they are forced to develop their own solutions and use nonspecialized software, such as Word and Excel in order to process HR data. The products are insufficiently localized for the country's needs and peculiarities.

3. It is necessary to develop such systems that will have a perfect price/quality balance, as they will be readily accepted and implemented in the market.

4. It is recommended to implement solutions on the basis of SaaS model, as it will be well-received by the customers and will solve all the necessary problems,

5. As long as there is not much competition in the Saudi market, it will be comparatively easy to implement new solutions if people are properly informed about its benefits.

\section{References}

1C Company (2012). http://en.wikipedia.org/wiki/1C_Company Accessed 12 July 2011.

Beaman, K., Doran, A., Henson, R., Krebs, V., et al. (2000). 21 Tomorrows: hr systems in the emerging workplace of the 21st century. Austin: Rector Duncan \& Associates, Inc.

Blokdijk, G. (2008). SaaS 100 success secrets. E-Book.

Bocij, P., Greasley, A., \& Hickie, S. (2008). Business information systems: technology, development and management. Essex: Pearson.

Chang, W. Y., Abu-Amara, H., \& Sanford, J. (2010). Transforming enterprise cloud services. Berlin: Springer.

Gatewood, R. D., Feild, H. S., \& Barrick, M. (2008). Human resource selection. Mason: Thomson SouthWestern.

Hatch, R. (2008). SaaS architecture, adoption and monetization of SaaS projects. London: The Art of Service Pty Ltd.

Heathfield, S. M. (2012). Human resources information systems. http://humanresources.about.com/od/ glossaryh/a/hris.htm. Accessed 10 July 2011.

Hendry, C. (1999). Human Resource Management: a strategic approach to employment. Bath: The Bath Press.

HR Systems Still Disappointing (2007). http://www.hrmguide.co.uk/systems/survey.htm. Accessed 14 July 2011.

Human Resource Management Systems (2012). http://www.bestpricecomputers.co.uk/glossary/humanresource-management-systems.htm. Accessed 11 July 2011.

Human Resources Systems (2011). http://hr.od.nih.gov/hrsystems/default.htm. Accessed 13 July 2011.

Hunter, I., Saunders, J., Boroughs, A., \& Constance, S. (2006). HR business partners (pp. 69-71). Aldershot: Gower.

Mather, T., Kumaraswamy, S., \& Latif, S. (2009). Cloud security and privacy: an enterprise perspective on risks and compliance. Sebastopol: O'Reilly Media, Inc.

Moe, J. E. (2010). Why SaaS may not be a good fit for HR. http://www.comparehris.com/Why-SaaS-MayNot-Be-A-Good-Fit-for-HR/. Accessed 14 July 2011.

Oshri, I., \& Kotlarsky, J. (2010). Global sourcing of information technology and business processes. Berlin: Springer. 
SAP Human Resource Management Systems (2012). http://en.wikipedia.org/wiki/SAP_Human_ Resource_Management_Systems. Accessed 10 July 2011.

Software as a Service (2012). http://en.wikipedia.org/wiki/Software as a service. Accessed 13 July 2011. The Evolution of HR Systems: Update from HR Technology Conference 2010 (2010). http://www.bersin. com/blog/post/2010/10/The-Evolution-of-HR-Systems-Update-from-HR-Technology-Conference2010.aspx. Accessed 14 July 2011.

The Facts about On-Demand HR Software (2012). http://www.sapiensoftware.com/saaspaper.aspx. Accessed 15 July 2011.

Velte, A. T., Velte, T. J., \& Elsenpeter, R (2010). Cloud computing: a practical approach. E-book

Williams, L. (2009). Beware the Pros and Cons of SaaS. http://www.hreonline.com/HRE/story.jsp? storyId=220825812. Accessed 15 July 2011. 